\title{
Violência Física Perpetrada por Ciúmes no Namoro de Adolescentes: Um recorte de Gênero em Dez Capitais Brasileiras
}

\author{
Queiti Batista Moreira Oliveira ${ }^{1}$ \\ Simone Gonçalves de Assis \\ Kathie Njaine \\ Thiago de Oliveira Pires \\ Escola Nacional de Saúde Pública Sergio Arouca \\ Fundação Oswaldo Cruz
}

\begin{abstract}
RESUMO - A violência entre namorados adolescentes vem ganhando visibilidade no âmbito científico, configurando-se como problema de saúde pública. Este estudo quanti-qualitativo investiga como questões de gênero permeiam a violência física perpetrada no namoro entre adolescentes. Realizou-se inquérito epidemiológico com 3.205 adolescentes (idades de 15 a 19 anos), estudantes do $2^{\circ}$ ano do Ensino Médio de escolas públicas e privadas de 10 capitais brasileiras. Entrevistas grupais e individuais foram também realizadas com 519 participantes. Humilhações e agressões entre namorados foram consideradas graves, entretanto, infidelidade e ciúme destacaram-se como disruptores de conflitos e brigas, refletindo normas de gênero tradicionais legitimadoras da violência. Destaca-se a necessidade de ações voltadas à desconstrução de estereótipos de gênero e à problematização da banalização da violência entre adolescentes.
\end{abstract}

Palavras-chave: Adolescência, gênero, violência conjugal, relações homem-mulher, ciúme, infidelidade

\section{Physical Violence Perpetrated by Jealousy in Adolescent Dating: A Gender Approach in Ten Brazilian Capitals}

\begin{abstract}
Adolescent dating violence has been gaining visibility in the scientific realm over the past three decades, being considered as a public health issue. This quantitative and qualitative study investigates gender influences in physical dating violence among Brazilian adolescents. A survey was conducted with 3,205 adolescents (15-19 years old) from 2nd year of high school of public and private schools in 10 Brazilian cities. Group and individual interviews were also conducted with 519 participants. Although humiliations e aggression between lovers were considered serious by most teenagers, infidelity and jealousy stood out as disruptors of conflicts and fights, reflecting traditional gender norms that legitimize violence. Programs aimed at deconstructing gender stereotypes and questioning the banalization of violence among adolescents are needed.
\end{abstract}

Keywords: Adolescence, gender, intimate partner violence, male female relations, jealousy, infidelity

O objetivo deste artigo é investigar questões de gênero e práticas de violência física perpetradas no namoro de adolescentes brasileiros. A violência entre namorados adolescentes vem ganhando visibilidade no âmbito científico ao longo das últimas três décadas. A partir da década de 80 , o tema entra na pauta de pesquisas norte-americanas e canadenses (O'Keefe, Brockopp \& Chew, 1986; Makepeace, 1981, 1986; Aizenman \& Kelley, 1988) e recentemente vem sendo estudado em outros países, como Portugal (Saavedra, Machado, Martin, \& Vieira, 2011), Espanha (FernandezFuertes \& Fuertes, 2010; Franco, Bellerín, Borrego, Díaz, \& Molleda, 2012), China (Shen, Chiu \& Gao, 2012), Suiça (Hamby, Nix, De Puy \& Monnier, 2012), Israel (Schiff \& Zeira, 2005), México (Ángel \& Barraza, 2015; Hokoda et al, 2006; Borrego, Franco, Diaz \& Moleda, 2014) e Brasil (Beserra et al., 2015; Gomez, Speizer, \& Moracco, 2011; Oliveira, Assis, Njaine, \& Oliveira, 2011).

1 Endereço para correspondência: Departamento de Estudos sobre Violência e Saúde Jorge Careli - CLAVES, Av. Brasil, 4036, sala 700, Manguinhos, Rio de Janeiro, Brasil. CEP: 21040-361. E-mail: queitibmoliveira@gmail.com
A prevalências da violência física no namoro varia sobremaneira em função dos diferentes métodos e conceituações utilizados, o que pode dificultar a constatação da real gravidade e extensão do problema (Borrego et al, 2014; Foshee \& Reyes, 2011). Entretanto, diversos estudos têm mostrado índices preocupantes de agressão entre namorados e a co-ocorrência de violência psicológica, física e sexual (Fernandez-Fuertes \& Fuertes, 2010; Sears, Byers, Whelan \& Saint-Pierre, 2006; Schiff \& Zeira, 2005). Estudos norte-americanos apresentam prevalências de agressão física perpetrada contra o parceiro no namoro que variam de $11 \%$ a 41\% (Foshee \& Reyes, 2011). As prevalências dos diversos tipos de agressões que podem ocorer no namoro mostramse similares entre meninos e meninas (Fernadez-Fuertes \& Fuertes, 2010; Malik, Sorenson, \& Aneshensel,1997; Molidor \& Tolman, 1998; Schiff \& Zeira, 2005; Wolfe, Scott, ReitzelJaffe, et al., 2001).

Direcionando o foco para pesquisas que utilizaram a escala Conflict in Adolescents Dating Relationships (CADRI; Wolfe Scott, Reitzel-Jaffe, et al., 2001), utilizada no presente artigo para aferição da violência entre namorados adolescentes, obtêm-se resultados similares de prevalência de 
adolescentes que já haviam perpetrado agressão física contra um namorado no Canadá, 24\% (Wolfe, Scott, Wekerle, et al., 2001), na Espanha, 24,3\% (Fernandez-Fuertes \& Fuertes, 2010), e no Brasil, 24,1\% (Oliveira, Assis, Njaine, \& Oliveira, 2011).Comparando os resultados entre os sexos, esses estudos mostram que as meninas apresentam mais relatos de perpetração de violência física contra um parceiro em um momento de conflito: no Brasil, 28,5\% das meninas frente a 16,8\% dos meninos (Oliveira, Assis, Njaine, \& Oliveira, 2011); entre os canadenses, $28 \%$ das meninas contra $11 \%$ dos meninos (Wolfe, Scott, Wekerle, et al., 2001); e entre os espanhóis, 30,2\% das meninas e 16,1\% dos meninos (Fernandez-Fuertes \& Fuertes, 2010). Em contrapartida, são os meninos que mais relatam terem sofrido violência física em uma relação de namoro: entre os brasileiros, 24,9\% dos meninos e 16,5\% das meninas (Oliveira, Assis, Njaine, \& Oliveira, 2011); entre os canadenses, 28\% dos meninos e 19\% das meninas (Wolfe, Scott, Wekerle, et al., 2001); e, por fim, entre os espanhóis, $26,3 \%$ dos meninos e $17,5 \%$ das meninas (Fernandez-Fuertes \& Fuertes, 2010).

Além de apresentar altas prevalências, a violência entre namorados adolescentes é considerada um forte preditor da violência entre casais na idade adulta (Cornelius, Sullivan, Wyngarden, \& Milliken, 2009; Frieze, 2000) e produz efeitos nefastos na saúde física e mental, bem como na qualidade de vida de quem a vivencia, tais como baixa autoestima, dores crônicas, ansiedade, entre outros (Cornelius et al., 2009; Foshee \& Reyes, 2011). Revisão sobre fatores protetivos e de risco para a perpetração de violência no namoro entre adolescentes lista 53 fatores de risco, agrupando-os em problemas de saúde mental, violência juvenil, uso de substâncias, comportamentos sexuais de risco, problemas de relacionamento e qualidade das amizades, problemas de relacionamento familiar, fatores demográficos e, por fim, violência na mídia. Alguns fatores de risco estiveram presentes em múltiplos estudos dessa revisão: depressão, agressão em geral, violência em namoros anteriores, raça/ etnia, vivência de violência entre pares, ter amigos que cometem violência no namoro, conflito conjugal entre os pais (Vagi et al, 2013).

Entende-se que a violência entre namorados é expressão da violência de gênero, pois se caracteriza por atos que geram danos físicos ou emocionais, perpetrados com abuso de poder de uma pessoa contra a outra, que acontecem em relações desiguais e assimétricas, produzidas por normas de gênero que são mecanismos por meio do qual são naturalizadas as noções de masculino e de feminino (Butler, 2010). Dito de outra forma, tais normas definem social e culturalmente o que é ser homem e ser mulher (Zuma, Mendes, Cavalcanti, \& Gomes, 2009). Nessas relações desiguais, via de regra, é o feminino que figura como o polo subalternizado e oprimido, o que rendeu ao termo "violência de gênero" a qualidade de sinônimo de violência contra a mulher, embora não se refira somente a esse tipo de violência (Dantas-Berger \& Giffin, 2005).

A violência no namoro pode trazer diversas consequências físicas, emocionais e sociais para os adolescentes (Foshee \& Reyes, 2011; Krug, Mercy, Dahlberg \& Zwi, 2002). Pautada em normas culturais tradicionais de gênero, que marcam os processos de socialização, a violência no namoro ocorre entre homens e mulheres e entre pessoas do mesmo sexo, embora as relações homoafetivas não tenham sido abordadas neste estudo (Gomes, Minayo, \& Silva, 2005; Saffiotti, 2004), e precisa ser entendida a partir de uma perspectiva relacional, entendendo a violência como uma forma de comunicação (Gregori, 1993).

Duas categorias são importantes nas análises deste estudo: patriarcado (Saffiotti, 2004) e dominação masculina (Bourdieu, 2011). Para Saffioti (2004), as categorias gênero, patriarcado e violências estão profundamente imbricadas, já que a cultura patriarcal, fortemente hierarquizante, tem a violência como um elemento constitutivo, com destaque para a "pedagogia da violência" (Saffioti, 2004, p.74), em que se banaliza o exercício do poder por meio da força e da dominação daqueles considerados hierarquicamente inferiores, com a anuência, o incentivo ou apenas a tolerância da sociedade.

Já a dominação masculina refere-se a uma lógica social androcêntrica que se inscreve nas coisas e nos corpos, por meio das práticas cotidianas, de forma sutil e tácita, que se traduz na incorporação da ordem masculina a partir das "rotinas da divisão social do trabalho, ou dos rituais coletivos e privados" que desvalorizam, subjugam e excluem o feminino (Bourdieu, 2011, p. 7). São mecanismos sutis de dominação e exclusão social que expressam uma submissão paradoxal que atravessa homens e mulheres, dominantes e dominados, de forma imperceptível, o que o autor chamou de violência simbólica.

No que se refere às possibilidades de escape às normativas de gênero, de transformação e de pluralidade de formas de vivenciar o ser homem e o ser mulher, este texto se apoia nas proposições de Judith Butler (2010). Ancorada nas proposições foucaultianas sobre o poder como exercício e como relação de forças, a autora recusa a noção de identidades de gênero fixas, imutáveis e a-históricas. Afirma que as normas de gênero são "contingenciais" e produzem identidades que se revelam de formas precárias, construídas por meio de "performances instituídas", repetições incorporadas de gestos, movimentos e estilos reproduzidos e atualizados ao longo do tempo, ou mesmo abandonados e esquecidos, conforme os contextos históricos e relacionais (Butler, 2010, p. 200).

O foco do presente artigo são as questões de gênero que permeiam a violência física perpetrada nas relações de namoro entre adolescentes, uma vez que grande parte dos estudos sobre esse tema e essa faixa etária privilegiam abordagens epidemiológicas com enfoque nas agressões/ vitimizações por sexo, mas não aprofundam as discussões sobre as relações de gênero (Tolman, Spencer, RosenReynoso, \& Porshe, 2003). Além disso, privilegia-se o diálogo com a literatura que trata de relacionamentos entre adolescentes, dadas as especificidades dessa etapa da vida, entre elas, o que Heilborn (2009) chamou de "aprendizado amoroso", quando as vivências das primeiras experiências afetivo-sexuais, em geral, estão em curso. Assim, acredita-se que este estudo possa contribuir para um maior conhecimento sobre a violência nas relações afetivosexuais na adolescência, bem como sobre as estratégias de prevenção, a partir da compreensão das práticas de violência 
física entre namorados adolescentes e das lógicas de gênero presentes nessas relações.

\section{Método}

\section{Participantes}

O presente estudo é um recorte de uma pesquisa quantiqualitativa realizada entre 2007 e 2009 com estudantes com idades entre 15 e 19 anos do $2^{\circ}$ ano do Ensino Médio de escolas públicas e privadas de 10 capitais brasileiras (Manaus/AM, Porto Velho/RO, Teresina/PI, Recife/PE, Cuiabá/MT, Brasília/DF, Rio de Janeiro/RJ, Belo Horizonte/ $\mathrm{MG}$, Florianópolis/SC e Porto Alegre/RS).

A pesquisa original teve como objetivo investigar a prevalência e as visões sobre violência no namoro de adolescentes que já tivessem vivenciado algum tipo de relacionamento afetivo-sexual (namorar ou ficar). Foi realizada através de triangulação metodológica do tipo métodos mistos convergentes, com os dados quantitativos e qualitativos coletados de forma concorrente, com integração dos dados realizada na etapa de interpretação e análise (Minayo, Souza, Constantino, \& Santos, 2005).

As dez cidades foram escolhidas por conveniência, utilizando como critérios a inclusão de localidades das cinco regiões brasileiras e a apresentação de elevados índices de morbimortalidade por causas externas na faixa de 1519 anos. Em cada cidade, a amostra é representativa das redes pública e privada, sendo realizada uma amostragem conglomerada multiestágio (escolha das escolas, com probabilidade de seleção proporcional à quantidade de alunos e seleção aleatória de uma turma por escola, com aplicação do questionário para todos os alunos). A amostra foi dimensionada para se obterem estimativas de proporção, com erro absoluto de 0,10 , nível de confiança de $95 \%$ e proporção (P) da ocorrência de vitimização entre namorados igual a $70 \%$. Foi inclú́do um efeito de desenho de pelo menos 2 (Oliveira, Assis, Njaine, Minayo, et al., 2011).

Participaram da abordagem quantitativa 3.205 adolescentes das dez cidades ( $62,0 \%$ do sexo feminino) e da abordagem qualitativa, 519 (50,5\% meninas). Esses bancos de dados oriundos da pesquisa original foram analisados no presente artigo.

\section{Instrumentos}

A abordagem quantitativa foi realizada através de inquérito epidemiológico com a aplicação de questionário fechado, autopreenchível e anônimo. O recorte feito no presente artigo inclui a escala CADRI na esfera da perpetração de agressão física (Wolfe Scott, Reitzel-Jaffe, et al., 2001) e quatro itens isolados. A CADRI afere a violência existente nas relações afetivo-sexuais entre adolescentes de natureza física, sexual e psicológica ( 25 itens sobre violência sofrida e 25 sobre violência perpetrada). $O$ instrumento passou por adaptação transcultural para a língua portuguesa (Avanci \& Assis, 2011). Os quatro itens da CADRI apresentados no presente artigo aferem perpetração de agressão física: jogar algo sobre o(a) parceiro(a); bater, chutar ou dar um soco; dar um tapa ou puxar o cabelo; e empurrar ou sacudir. Os itens foram analisados através da frequência de ocorrência do fato $(0$ nunca, 1- raramente, 2- algumas vezes e 3-frequentemente). A presença da agressão ocorre quando o escore da soma dos quatro itens for igual a um ou superior. A CADRI não afere intensidade do dano provocado pelas agressões físicas.

Outras quatro questões investigadas neste artigo referemse à concordância com a humilhação e a agressão física de uma forma geral e em situações que envolvam infidelidade: (a) considerar grave/muito grave/não grave um(a) namorado(a) humilhar o namorado(a); (b) considerar grave/ muito grave/ não grave namorado(a) agredir namorado(a); (c) concordar ou discordar com o direito de um(a) garoto(a) agredir outro(a) que esteja dando em cima de seu(sua) namorado(a); (d) concordar ou discordar com a ideia de que se o(a) garoto(a) foi infiel ao(à) seu(sua) namorado(a), ele(a) merece apanhar. Tais questões foram elaboradas pelo grupo de pesquisa em trabalhos anteriores (Minayo, Assis, Njaine, et al., 1999; Minayo, Njaine, \& Assis, 2004), que indicaram a relevância da humilhação (sinônimo de violência psicológica) e da agressão (análogo da violência física). O sentimento de ciúme provocado por situações de infidelidade (real ou suposta) é desencadeador de conflitos que resultam em violência durante o namoro em contextos culturais distintos (Fernandéz-Fuertes \& Fuertes, 2010; Follingstad et al., 1991; Jaycox et al., 2000; Molidor \&Tolman, 1998) e no cenário nacional (Gomez, Speizer, \& Moracco, 2011; Oliveira, Assis, Njaine, Minayo, et al., 2011; Taquette, Ruzany, Meirelles, \& Ricardo, 2003). Além disso, entende-se que a relação entre ciúme e violência dá visibilidade a normas de gênero presentes nos relacionamentos.

$\mathrm{Na}$ abordagem qualitativa, foram elaborados roteiros de entrevista semiestruturada aplicados aos adolescentes, em sua maioria através de grupos focais. Entrevistas individuais foram feitas com $8,6 \%$ do total de jovens, visando oferecer respostas personalizadas. Os itens analisados no artigo tratam dos tipos de relações amorosas, opiniões e sentimentos dos jovens sobre as relações de namoro e sobre violência no namoro, especificamente sobre as agressões físicas.

\section{Procedimentos}

A coleta de dados foi feita integralmente para o estudo original. Para a análise quantitativa, foram realizadas análises de frequência e de associação entre a CADRI e as quatro variáveis que aferem a concordância com a humilhação e a agressão física. Foi utilizado o F ajustado (teste de Rao-Scott; nível de significância de $p<0,05$ ) e conduzidos modelos de regressão logística univariados para estimativa das medidas de associação bruta (Razão de Chance) e seus respectivos intervalos de confiança de 95\%. Para os modelos ajustados, foram incorporados os desenhos amostrais para correção dos erros padrões e a introdução dos pesos amostrais para correção das estimativas pontuais.

$\mathrm{Na}$ abordagem qualitativa, realizaram-se seis grupos focais ( 2 femininos, 2 masculinos e 2 mistos) e seis entrevistas individuais ( 3 femininos e 3 masculinos) em 
cada uma das dez cidades, totalizando a participação de 519 adolescentes. As falas apresentadas distinguem sexo; grupo focal (GF) misto, masculino ou feminino; ou entrevista individual (EI). As informações foram organizadas segundo a técnica de análise de conteúdo categorial temática (Bardin, 2011) e analisadas e interpretadas com base em constructos teóricos sobre gênero (Butler, 2010; Bourdieu, 2011; Saffioti, 1987, 2004).

O estudo foi aprovado pelo Comitê de Ética em Pesquisa da Escola Nacional de Saúde Pública/Fundação Oswaldo Cruz (No 07/20008). Foi obtida autorização das Secretarias Estaduais de Educação e dos diretores das escolas visitadas, bem como dos estudantes (em algumas escolas, também dos pais), que assinaram Termo de Consentimento Livre e Esclarecido.

\section{Resultados}

Os relatos dos adolescentes destacam o ciúme e a infidelidade como fatores que legitimam e justificam as agressões físicas entre namorados, tanto por parte dos meninos, quanto por parte das meninas. Tal legitimidade encontra respaldo em normas de gênero que se expressam na violência como construção da masculinidade, na banalização da violência física feminina e na violência física contra meninas perpetradas por ambos os sexos.

\section{O Ciúme e a Infidelidade Legitimando as Agressões Físicas}

Conforme pode ser constatado na Tabela 1, em relação à garota humilhar ou agredir o namorado, a maioria das respondentes avalia esses atos como graves ou muito graves (acima de 90\% do total), independente da prática pessoal ou não de agressão física no namoro. Quando, porém, acrescentam-se motivações para as agressões físicas embasadas em ciúmes ou fundamentadas na exigência de fidelidade no relacionamento afetivo, cresce substancialmente o percentual de garotas que concorda com a legitimidade das agressões físicas. Visto de outra forma, na Tabela 1, percebe-se que as meninas que concordam com o ato de agredir outra garota por estar dando em cima de seu namorado têm mais chances $(\mathrm{OR}=3,05)$ de praticar agressão física no namoro se comparadas àquelas que discordam de tal ato. No que se refere à concordância com o fato de uma garota apanhar do namorado por infidelidade no namoro, a chance daquelas que perpetram agressão física na relação afetivo-sexual é 3,2 vezes maior se comparada com as garotas que discordam de tal ato.

Assim como observado em relação ao próprio sexo, $98 \%$ das garotas consideram grave ou muito grave o ato de os rapazes humilharem e agredirem as namoradas, sem diferenças significativas entre as que já agrediram fisicamente seus parceiros em um relacionamento afetivosexual e as que nunca agrediram. Quanto às agressões motivadas pela infidelidade do garoto, as meninas que já praticaram agressões físicas no namoro concordam bem mais $(\mathrm{OR}=3,65)$ que o rapaz merece apanhar, em relação às que nunca praticaram agressão física no namoro. Não se notou distinção estatisticamente significativa em relação ao item "o garoto tem direito de agredir outro que esteja dando em cima de sua namorada".

Quando se compara a visão das meninas em relação ao sexo feminino e masculino, verifica-se que as garotas, em sua maioria, condenam as agressões físicas e as humilhações no namoro, mas, principalmente, aquelas praticadas pelos meninos contra suas namoradas. Todavia, garotas se colocam com mais direitos de agredir outra que esteja dando em cima do namorado do que admitem para o mesmo fato no sexo oposto. Dito de outra forma, elas concordam mais com a agressão entre garotas, por ciúme do namorado, do que com a agressão entre garotos, por ciúme das namoradas. Já no que se refere a apanhar em caso de infidelidade, meninas se julgam menos merecedoras.

Tal qual observado entre as meninas, mais de 93\% dos garotos consideram muito grave ou grave que o namorado humilhe ou agrida a namorada (Tabela 2). O direito de agredir outro rapaz que esteja dando em cima da namorada é informado por um número grande de rapazes, indicando, mais uma vez, o ciúme como um fator que motivaria a agressão física. Essa realidade é mais cristalizada entre os rapazes perpetradores de agressão física no namoro $(\mathrm{OR}=2,41)$.

Concordar com a afirmativa de que o garoto infiel à namorada merece apanhar foi mencionado por muitos rapazes. Entre aqueles perpetradores de agressão física no namoro, nota-se maior concordância com tal visão $(\mathrm{OR}=2,14)$. A maioria dos garotos afirma que a namorada humilhar e agredir o namorado é muito grave/grave, no entanto, muitos concordam com o merecimento de a garota agredir outra que esteja dando em cima do namorado, com uma $\mathrm{OR}=2,15$, indicando a maior perpetração de agressão física entre os rapazes que concordam com tal afirmativa. Entre os rapazes que relataram já terem praticado agressão física no namoro, os que acham que a namorada merece apanhar se tiver sido infiel ao namorado mostraram maior chance $(\mathrm{OR}=3,35)$ de perpetração de agressão física no namoro.

Comparando-se a visão dos garotos em relação ao próprio sexo e ao oposto, notam-se mais similaridades do que diferenças. Destaca-se apenas o direito de agredir outro por ciúme, que é mais legitimado para o sexo masculino.

Comparando meninos e meninas no que tange à agressão física a outra pessoa por ciúme do parceiro(a), entre as meninas (Tabela 1), percebe-se que, embora os índices tenham sido menores em comparação aos garotos (Tabela 2), os dados sugerem uma aceitação muito maior da agressão de uma garota contra outra por ciúme do namorado do que da agressão entre meninos por ciúme da namorada. Entre os meninos, embora esse tipo de agressão tenha apresentado altos índices (Tabela 2), não houve, todavia, grandes diferenças entre as visões de meninos e meninas.

Embora tenha sido comum o discurso chancelado socialmente de que a violência não é a melhor maneira de resolver conflitos, a infidelidade é usada como justificativa para as agressões, tanto pelos meninos quanto pelas meninas. O sentimento de ciúme provocado pela infidelidade, real ou apenas suposta, é apontado como principal disparador dos conflitos no namoro, conflitos esses que podem evoluir para 
Tabela 1. Opinião de adolescentes do sexo feminino em relação ao próprio sexo e do sexo oposto sobre humilhações, agressões e infidelidade entre namoradoseà prática de violência física nos relacionamentos afetivo-sexuais

Opinião sobre humilhações, agressões e infidelidade entre namorados
Categorias

OR (IC)

\begin{tabular}{cccc}
\multicolumn{3}{c}{ Agressãofísicaperpetrada } \\
\hline \multicolumn{2}{c}{ Sim } & \multicolumn{2}{c}{ Não } \\
\hline N & $\%$ & N & $\%$
\end{tabular}

EM RELAÇÃO AO PRÓPRIO SEXO

Você considera que a namorada humilhar o namorado é:

Você considera que a namorada agredir o namorado é:

A garota tem direito de agredir outra que esteja dando em cima de seu namorado.

Se a garota foi infiel ao seu namorado, ela merece apanhar.

Você considera que o namorado humilhar a namorada é:

Você considera que o namorado agredir a namorada é:

O garoto tem direito de agredir outro que esteja dando em cima de sua namorada

Se o garoto foi infiel a sua namorada, ele merece apanhar

\begin{tabular}{llllll} 
Muito grave/ grave & 482 & 91,2 & 1267 & 94,1 & $1,52(0,86-2,69)$ \\
Não é grave & 46 & 8,8 & 56 & 5,9 & \\
Muito grave/ grave & 481 & 94,6 & 1278 & 95,7 & $1,23(0,45-3,37)$ \\
Não é grave & 43 & 5,3 & 45 & 4,4 & \\
Concordo & 151 & 35,4 & 161 & 15,3 & \multirow{2}{*}{$3,05(1,58-5,90)^{*}$} \\
Discordo & 345 & 64,6 & 1.079 & 84,7 & \\
Concordo & 69 & 19,1 & 79 & 6,9 & $3,20(1,21-8,45)^{*}$ \\
& 425 & 80,9 & 1.199 & 93,1 & \\
EM RELAÇÃO AO SEXO OPOSTO & & & & \\
Muito grave/ grave & 519 & 98.9 & 1309 & 98,0 & $0,56(0,17-1,88)$ \\
Não é grave & 9 & 1,1 & 15 & 2,0 & \\
Muito grave/ grave & 527 & 100,0 & 1321 & 99,1 & \\
Não é grave & 0 & 0,0 & 4 & 0,9 & \\
Concordo & 96 & 18,8 & 95 & 8,8 & \multirow{2}{*}{$2,41(0,86-6,76)$} \\
Discordo & 390 & 81,2 & 1.135 & 91,2 & \\
Concordo & 192 & 44,1 & 233 & 17,8 & $3,65(2,01-6,63)^{*}$ \\
Discordo & & & & & \\
\hline
\end{tabular}

Nota. Associações estatisticamente significativas ao nível de $p<0,05$

Tabela 2. Opinião de adolescentes do sexo masculino em relação ao próprio sexo e ao sexo oposto sobre humilhações, agressões e infidelidade entre namorados e à prática de violência física nos relacionamentos afetivo-sexuais

\section{Opinião sobre humilhações, agressões e infidelidade entre namorados}

Categorias
OR (IC)

\begin{tabular}{cccc}
\hline \multicolumn{2}{c}{ Sim } & \multicolumn{2}{c}{ Não } \\
\hline N & $\%$ & N & $\%$
\end{tabular}

\section{EM RELAÇÃO AO PRÓPRIO SEXO}

Você considera que o namorado humilhar a namorada é:

Você considera que o namorado agredir a namorada é:

$\mathrm{O}$ garoto tem direito de agredir outro que esteja dando em cima de sua namorada

Se o garoto foi infiel a sua namorada, ele merece apanhar

Você considera que a namorada humilhar o namorado é:

Você considera que a namorada agredir o namorado é:

A garota tem direito de agredir outra que esteja dando em cima de seu namorado:

Se a garota foi infiel ao seu namorado, ela merece apanhar

\begin{tabular}{llllll} 
Muito grave/ grave & 171 & 93,3 & 1003 & 93,6 & $1,05(0,39-2,82)$ \\
Não é grave & 23 & 6,7 & 57 & 6,4 & \\
Muito grave/ grave & 182 & 96,3 & 1046 & 97,8 & $1,65(0,22-12,6)$ \\
Não é grave & 12 & 3,7 & 14 & 2,2 & \\
Concordo & 117 & 69,8 & 443 & 48,9 & \multirow{2}{*}{$2,42(1,55-3,77)^{*}$} \\
Discordo & 64 & 30,2 & 498 & 51,1 & \\
Concordo & 35 & 33,9 & 186 & 19,3 & \multirow{2}{*}{$2,14(1,17-3,95)^{*}$} \\
& 142 & 66,1 & 771 & 80,7 & \\
M RELAÇÃO AO SEXO OPOSTO & & & & \\
Muito grave/ grave & 180 & 95,9 & 1014 & 95,8 & \multirow{2}{*}{$0,97(0,35-2,66)$} \\
Não é grave & 14 & 4,1 & 45 & 4,2 & \\
Muito grave/ grave & 171 & 89,4 & 1004 & 96,8 & \multirow{2}{*}{$3,62(0,83-15,8)$} \\
Não é grave & 22 & 10,6 & 48 & 3,2 & \\
Concordo & 90 & 53,5 & 307 & 34,9 & $2,15(1,36-3,41)^{*}$ \\
Discordo & 85 & 46,5 & 606 & 65,1 & \\
Concordo & 58 & 40,9 & 158 & 17,1 & $3,35(1,67-6,75)^{*}$ \\
& 117 & 59,1 & 795 & 82,9 & \\
\hline
\end{tabular}

Nota. Associações estatisticamente significativas ao nível de $p<0,05$ 
brigas e atitudes violentas entre os parceiros. Associado ao cuidado entre aqueles que se amam, o ciúme é percebido como negativo pelos adolescentes somente quando é considerado exagerado, manifestando-se através de comportamentos controladores ou de agressões diversas, inclusive físicas: "o ciúme obsessivo coincide com a violência" (garota, GF misto).O comportamento controlador mostrou-se comum entre ambos os sexos, com meninas considerando os garotos mais controladores e ciumentos, em contraposição aos garotos, que, por sua vez, sentem-se mais controlados e cerceados em sua liberdade por suas namoradas.

\section{Violência como Construção da Masculinidade e a Banalização da Violência Física Feminina}

A violência como construção da masculinidade se expressa nos relatos de meninos e meninas quando qualificam a agressão física como algo intrínseco ao ser homem e percebem-na como algo mais praticado pelos namorados contra suas parceiras do que o contrário. Nesse contexto, sentir-se traído foi considerado bastante grave pelos adolescentes do sexo masculino, para quem a traição seria uma forma de humilhação, podendo provocar atitudes impulsivas e violentas:

A traição é o inimigo do cara (garoto, GF misto).

A agressão fisica aparece no discurso dos meninos como parte do ser homem:

...o homem é um pouquinho ignorante. A gente acha que

é melhor do que as mulheres. Quer mostrar que tem mais

força, que é superior a elas. E vai querer bater e não agredir verbalmente. (garoto, EI)

Por outro lado, persiste a crença de que a infidelidade masculina é da natureza do homem, o que os licencia a trair ou ter várias garotas. $\mathrm{O}$ diálogo de meninos evidencia esses valores: "Trair não é violência" (garoto 1); "Se a mulher trair é!" (garoto 2); "Na verdade isso é desde a pré-história...o homem pode, e a mulher não" (garoto 3). Ser "traído", no entanto, é uma situação inaceitável pelos garotos durante o namoro, ou mesmo o fato da menina ter muitos amigos homens ou provocar admiração em outros garotos

Foram poucos relatos de agressões físicas contra os namorados praticadas por meninas. Quando citada, a agressão física foi justificada por ser uma forma de revidar outra agressão: "ele não queria que eu saísse, aí ele me puxou e me deu um tapa (...) e eu também fui pra cima dele!" (garota, GF feminino). Os tapas são o tipo de agressão física mais praticado pelas meninas e precedem ou ocorrem concomitantemente às ameaças, às agressões verbais e comportamentos controladores, como, por exemplo, a conferência de conteúdos dos celulares dos namorados e de seus perfis em redes de relacionamentos na internet.

Embora percebidos como menos frequentes e como um recurso de defesa, a agressão das garotas contra seus parceiros é considerada banal por adolescentes de ambos os sexos, uma vez que não traz danos físicos graves.

A agressão de uma mulher para um homem é totalmente diferente (...)um tapa de uma mulher não dói! (garota, GF misto) Se uma mulher me dá um tapa, eu não vou fazer nada... porque se eu for dar nela, eu quebro ela no cacete. O que é uma mulher, por mais brava que ela seja?... é uma pessoa sensível. Ela é feita de impulso, tem que saber levar (garoto, GF misto)

Contudo, se, por um lado, a agressão feminina é desqualificada, por outro, sua banalização foi bastante questionada pelos meninos, diante, sobretudo, da impossibilidade do revide imposto pela sanção social à violência contra a mulher:

Homem não pode bater em mulher, mas a mulher bate na gente!

Ela aqui te batendo e você tem medo de encostar nela por que é considerado uma agressão (garotos, GF masculino).

Reiterando essa lógica de banalização da agressão feminina, tem-se que os garotos percebem-na como humilhação, preocupando-se muito mais com os efeitos em sua moral do que com os possíveis danos físicos:

Eu levei um tapa na cara de uma namorada uma vez só. Aceitei. Uma vez a gente recebe o tapa. O homem não vai querer ficar levando tapa na cara de mulher. O tapa na cara do garoto: humilhação. É como estar submisso à mulher. (garoto, GF misto)

Para além do revide, a agressão física da namorada contra o namorado representa também, para as garotas, a recusa em ocupar um lugar submisso frente ao parceiro, produzindo reações fisicamente violentas às investidas opressoras, controladoras e agressivas por parte dos namorados. Há uma combinação entre a rejeição da violência contra a mulher fruto de todo contexto histórico-político de luta que ganha crescente visibilidade - e de afirmação de um lugar de poder nos mesmos moldes da subjugação tradicional de mulheres frente aos homens: "Eu acho que agora [a mulher] tá querendo reagir. O que estava guardado há muito tempo... e de mulher se transforma em homem..." (garota, GF misto).

\section{Agressão Física contra Meninas Perpetradas por ambos os Sexos}

A relação assimétrica entre os gêneros também se expressa em relatos em que as meninas podem sofrer violências físicas tanto por parte de seus namorados quanto por parte de outras garotas, sendo o grande motivador o ciúme. Entre as meninas, as agressões de uma garota contra a outra por ciúmes do namorado são corriqueiras, graves e tidas como justificáveis. Agredir outra garota considerada rival foi muito mais relatado pelas meninas, do que as agressões aos próprios namorados considerados infiéis:

Se vê o cara com outra menina, vai [agredir] pegar a menina

de couro. (garota, GF feminino)

Estávamos em uma festa e eu fui pegar vinho (...) na hora que voltei uma menina estava querendo dançar com meu namorado... dei um soco só nela. (garota, GF feminino)

A agressão entre garotos por ciúmes da namorada, entretanto, não foi um tema de destaque na abordagem qualitativa tanto para os meninos quanto para as meninas. Isso pode indicar tanto uma naturalização das agressões por ciúmes quanto sua baixa ocorrência, justificada pela lealdade entre pares do sexo masculino.

A agressão física contra as garotas - rivais ou namoradas "infiéis" - foi justificada, por ambos os sexos, sobretudo pelo comportamento das próprias vítimas expressarem pouco ou nenhum controle sobre sua sexualidade, falta de recato, ou 
seja, não se adequando aos padrões tracionais de gênero. A figura da mulher "vagabunda", "desfrutável", emerge no discurso de ambos os sexos como provocadora de ciúmes entre os namorados, revelando preconceitos vigentes no senso comum que frequentemente incitam agressões morais e físicas, muitas vezes naturalizadas sob o manto da moralidade. A violência das agressões entre meninas por conta de disputas por namorados merece maiores investigações.

\section{Discussão}

A infidelidade e o ciúme destacaram-se como disruptores de conflitos e brigas durante o namoro. Se, por um lado, as humilhações e as agressões entre namorados foram atos considerados graves pela maior parte dos adolescentes - tanto por aqueles que já agrediram fisicamente um parceiro, quanto pelos que não agrediram -, por outro, houve maior aceitação de condutas violentas com o parceiro entre aqueles que já praticaram agressão física no namoro. Tal resultado coaduna com os de outros estudos, que indicam que, de forma geral, há uma não aceitação da violência no namoro, embora muitos jovens afirmem que algum comportamento abusivo possa ser aceito, como, por exemplo, o controle do outro através da censura de roupas e telefonemas, cerceamento da liberdade (Feiring, Deblimger, Hoch-Espada, \& Haworth, 2002; O'Keefe, 1997). Além disso, outros autores notam, como nós, que os adolescentes que percebem o uso da violência como uma resposta legítima nas relações de namoro são mais propensos a cometer ou sofrer violência (Foshee \& Reyes, 2001; O’Keefe \& Treister, 1998).

O sentimento de ciúme provocado pela infidelidade - real ou suposta - foi um elemento importante entre os adolescentes no tange à justificativa para as agressões aos parceiros. Nota-se, entre os adolescentes brasileiros, significativa concordância com a ideia de que o parceiro merece apanhar se foi infiel e com o direito de agredir outra pessoa por ciúmes de seu parceiro, sobretudo entre aqueles que praticaram violência física no namoro. Tanto meninos quanto meninas se acham com mais direitos de agredir por ciúme. Nesse sentido, o presente estudo vai ao encontro da literatura que indica que o ciúme é um importante disparador de conflitos em relações afetivo-sexuais entre adolescentes (Follingstad et al, 1991; Gomez et al., 2011; Jaycox et al., 2000), levando, por vezes, a comportamentos violentos (Fernandez-Fuertes \& Fuertes, 2010; Molidor \& Tolman, 1998).

Além de motivar agressões físicas, o ciúme é também valorizado pelos adolescentes como uma expressão de amor e cuidado. Em estudo com jovens brasileiros, Nascimento e Cordeiro (2011) mostram que comportamentos controladores, cerceamento da liberdade do outro, xingamentos e tapas, muitas vezes, são percebidos como brincadeiras entre namorados. As atitudes controladoras estão também relacionadas a um compromisso com o parceiro, e, como alerta Gamache (1991), é frequente que vítimas de agressões confundam atos controladores e ciúmes com atenção, prova de amor e preocupação por parte do abusador. Sears et al. (2006) afirmam que, para os adolescentes, um comportamento que expresse ciúme, ou mesmo uma agressão física, pode ser considerado abusivo e violento em um contexto, mas não em outro. O ciúme, então, pode ser percebido como violência se ocorre junto com uma ameaça de agressão física ou se ocorre de forma reiterada e frequente; no entanto, pode não ser tido como abusivo se for percebido como "brincadeira" ou como demonstração de carinho e cuidado por parte do parceiro. Essa associação entre ciúme e expressão de amor, de cuidado e de atenção entre parceiros íntimos é algo preocupante, pois é naturalizada na cultura ocidental e, portanto, permeia o aprendizado amoroso dos adolescentes (Heilborn, 2009).

No presente estudo, também percebemos, em ambos os sexos, uma maior legitimidade/aceitação da agressão feminina e maior condenação da agressão masculina. As agressões físicas praticadas pelas garotas foram desqualificadas pelos adolescentes participantes deste estudo, principalmente por serem consideradas de menor potencial ofensivo e danoso. Em contrapartida, a violência masculina é mais repudiada pelos adolescentes por também sê-lo socialmente, além de possuir maior visibilidade e ser considerada mais danosa. Esses resultados refletem os de pesquisas anteriores que mostram que os adolescentes de ambos os sexos aceitam mais o uso da violência física das meninas do que dos meninos (Sears et al., 2006), embora a violência feminina não se iguale à masculina no que se refere à frequencia, intensidade e severidade, às consequencias e ao senso de segurança e bem-estar da vítima (Dobash \& Dobash, 2004). De fato, há uma real desvantagem das mulheres em relação aos homens na vitimização por agressões entre parceiros íntimos: elas têm três vezes mais chances de serem feridas, cinco vezes mais chances de receberem assistência médica em função de um dano físico provocado pelo parceiro e cinco vezes mais medo de morrer (Krug et al, 2002).

Entretanto, tais dados se referem a estudos sobre violência entre parceiros adultos. Os níveis de violência entre parceiros íntimos variam de acordo com a idade do casal. Alguns dos primeiros indícios de agressão física perpetrada pelo sexo feminino contra alguém do sexo masculino vieram justamente dos estudos sobre casais de namorados em faculdades e escolas secundárias, que revelam frequências mais elevadas de agressão física, especialmente em adolescentes, do que o encontrado em relacionamentos de longo prazo entre casais mais velhos (Frieze, 2005). Além disso, tem-se revelado uma simetria, infeliz entre meninos e meninas na prática das agressões em geral, inclusive físicas. Entre jovens universitários paulistas, por exemplo, identifica-se uma equivalência entre agressões praticadas somente por um dos sexos (13,2\% para homens $14,5 \%$ para mulheres; Aldrighi, 2004). Acrescenta-se, ainda, um importante dado para compreendermos as agressões entre namorados adolescentes: diversos estudos mostram que as meninas têm reportado agredirem mais seus parceiros, inclusive fisicamente. (Fernadez-Fuertes \& Fuertes, 2010; Furlong et al., 2005; Malik et al., 1997; Schiff \&Zeira, 2005). Revisão crítica sobre estudos de prevalência de violências perpetradas por mulheres em relacionamento heterossexuais mostra altos índices de violência emocional, seguida por violência física e sexual (Williams, Ghandour, \& Kub, 2008). Entre os adolescentes brasileiros, por exemplo, $28,5 \%$ das garotas praticaram algum tipo de agressão física no namoro 
contra 16,8\% dos garotos (Oliveira, Assis, Njaine, Minayo, et al., 2011).

O que estaria em jogo, portanto, na banalização das agressões das meninas contra seus parceiros? No presente estudo, a violência física é percebida como algo masculino, reiterando outras pesquisas em que há uma percepção entre os adolescentes de que meninos utilizam a violência física mais do que meninas, apesar de dados de prevalência indicarem que meninos e meninas praticam violência física contra seus parceiros em níveis semelhantes (Roscoe \& Callahan, 1985; Sears et al., 2006).

Arriaga e Foshee (2004) identificaram que, embora as taxas de vitimização e perpetração fossem semelhantes entre os sexos, as meninas eram mais propensas a perpetrar agressões moderadas contra os parceiros, mas eram também mais propensas a serem vítimas de agressões graves. Da mesma forma, Frieze (2005), Malik et al. (1997) e Molidor e Tolman (1998) argumentam que os homens são mais propensos a praticar agressões físicas graves contra suas parceiras, sendo, por outro lado, mais propensos a serem vítimas de agressões de intensidade moderada, corroborando a pesquisa da Organização Mundial de Saúde (Krug et al., 2002). A exceção fica com o estudo brasileiro com universitários que mostra equivalência entre os sexos não só nos índices de agressões leves perpetradas, mas também no de severas: $23,1 \%$ das moças, $22,5 \%$ dos rapazes (Aldrighi, 2004).Segundo (Sears et al., 2006), trabalhos anteriores têm registrado que os jovens explicam essa diferença pela maneira distinta pela qual meninos e meninas costumam lidar com situações estressantes. Tais peculiaridades repousam justamente no processo de socialização a partir de normas de gênero, em que meninos não são incentivados a falar sobre seus sentimentos ou problemas, ao mesmo tempo em que são incentivados a demonstrar uma masculinidade viril que se afirma pela violência. Isso faz com que meninos contenham seus sentimentos ao ponto de, em uma situação estressante, explodirem fisicamente e/ou emocionalmente. Em contraposição, meninas teriam mais liberdade e incentivo para expressarem sua raiva verbalmente, e não fisicamente, e, por isso, teriam mais opções para lidar com sentimentos intensos (Sears et al., 2006). Esse mesmo tipo de discurso embasou as falas dos adolescentes participantes do nosso estudo.

Reiterando essa lógica de banalização da agressão feminina, tem-se que os garotos percebem-na como humilhação, preocupando-se muito mais com os efeitos em sua moral do que com os possíveis danos físicos. Nesse sentido, Sears et al. (2006) apontam para algumas especificidades nas representações da violência: os meninos tendem a descrever comportamentos como abusivos se a intenção foi negativa, enquanto as meninas tendem a descrever comportamentos como abusivos se o impacto foi negativo. Relatam ainda que alguns comportamentos, como o controlador, podem ser vistos como agressão psicológica quando advindos de uma menina, mas, quando vêm de um menino, podem ser vistos como cuidado e atenção, criando a impressão de que as meninas se envolvem em abuso psicológico com mais freqüência que os meninos. Da mesma forma, alguns comportamentos como bater, provavelmente são mais percebidos como abuso físico quando partem de um menino.

Além de a violência praticada pelas meninas ser considerada menos danosa, outra especificidade de gênero encontrada neste estudo, que ajuda a compreender a lógica da agressão feminina no namoro entre adolescentes, diz respeito à perpetração de agressões físicas como forma de revide $\mathrm{e}$ autodefesa frente a agressões sofridas por seus parceiros. Também mencionada em diferentes pesquisas (O'Keefe, 1997), tal forma de lidar com a violência sofrida nos leva a refletir sobre outro aspecto importante dos resultados do presente estudo que também leva a compreender a maior aceitação das agressões das adolescentes no namoro: a não aceitação da submissão e das agressões sofridas por parte das meninas. Nossos resultados levam à reflexão sobre tal prática, que vem sendo associada ao alcance de certo "patamar de igualdade" pelas meninas em relação aos meninos, o que, para nós, é preocupante, pois indica que a violência, inclusive a física, vem sendo vista como um meio através do qual tal igualdade poderia ser alcançada.

Por um lado, temos os altos percentuais de agressões físicas por parte das meninas se contrapondo à visão que os adolescentes têm sobre tais agressões - como atos tipicamente masculinos, refletindo padrões tradicionais da violência de gênero arraigados em nossa cultura. Desse modo, embora meninas pratiquem agressões físicas, estas ainda são reconhecidas pelos adolescentes como algo masculino. Por outro lado, tal reconhecimento da violência física como algo próprio da masculinidade também emerge nas explicações dadas pelas meninas sobre o porquê se utilizam de tais estratégias violentas no namoro: quando agridem estão se utilizando de estratégias de afirmação de poder por elas consideradas masculinas, em oposição ao lugar submisso tradicionalmente imposto ao feminino em nossa cultura machista e patriarcal. Não estariam as meninas operando na mesma lógica de controle do outro através da violência - hoje tão combatida e criticada - não só socialmente, como também juridicamente? Algo a ser melhor compreendido em estudos futuros.

Diante da maior condescendência com as agressões físicas cometidas pelas adolescentes, temos, em contrapartida, grande rejeição à violência praticada pelos meninos, o que reflete uma sanção já bastante presente na sociedade brasileira à violencia masculina entre parceiros íntimos. Sears et al.(2006) observam que os adolescentes percebem que os meninos estão praticando agressões físicas com menos frequência do que no passado, reconhecendo essa tendência como uma resposta deles à experiência social de sanções quando são fisicamente agressivos com suas namoradas. Tal situação é trazida, neste estudo, sob a forma de questionamento, sobretudo por parte dos meninos, de que as agressões cometidas pelas namoradas não podem ser alvo de revide dos namorados justamente pelas sanções - sociais e jurídicas - hoje existentes no Brasil, como a Lei Maria da Penha (Brasil, 2006), e pelas representações sobre o feminino como sexo frágil, das mulheres como pessoas mais sensíveis, mais fracas, o que, de certa forma, refrearia possíveis investidas fisicamente agressivas contra as mesmas.

Sobre a agressão física contra meninas perpetrada por ambos os sexos, vemos ainda que as meninas seguem como 
as maiores vítimas de agressões físicas, não só por seus parceiros, mas por outras garotas que as considerem rivais de alguma forma. E, nesse cenário, vemos mais uma vez que as meninas que agridem a "rival" assumem o discurso masculino do agressor que, frequentemente, recusa-se a aceitar a responsabilidade por suas ações, afirmando que a violência praticada é provocada pela própria vítima e que estaria de acordo com seus direitos de puni-la (Gamache, 1991), sobretudo quando a provocação se relaciona à conduta menos contida da menina no que se refere ao exercício da sexualidade ou do uso do próprio corpo.

Do ponto de vista de uma análise de gênero, podemos refletir que os resultados mostram que está presente entre os adolescentes uma lógica machista e androcêntrica baseada no patriarcado, como diz Saffioti (1987, 2004), ou na dominação masculina, como apresentada por Bourdieu (2011). Embora bastante reconhecida na socialização dos meninos brasileiros, podemos reconhecer tal lógica também nos discursos das meninas participantes deste estudo, segundo os quais o parceiro amoroso é algo que lhes pertence, gerando o sentimento de posse que se expressa no ciúme e na agressão física legitimada.

A punição física à infidelidade é um traço característico da cultura patriarcal que se fundamenta na banalização da violência e conta, ainda, com certa tolerância, quando não incentivo, da sociedade em relação ao exercício do poder através da força e da dominação daqueles considerados hierarquicamente inferiores. Trata-se de uma expressão de poder fortemente hierarquizada que ratifica uma "pedagogia da violência" (Saffioti, 2004, p.74). Nossos resultados apontam para a atualização de traços patriarcais não só entre os meninos, mas também entre as meninas, concretizando o que Fávero (2010) destaca como "patriarcado contemporâneo" (p. 74), não apenas devido aos índices de aceitação da agressão física por infidelidade, mas também pelos sentidos atribuídos a essa prática, sobretudo no que diz respeito ao sentimento de posse em relação ao parceiro e às agressões físicas contra meninas por ambos os sexos. Nesse sentido, Saffioti (2004) afirma que a mulher também é violenta no exercício da lógica patriarcal, mas destaca o quanto isso é baseado no androcentrismo, ou seja, independente do sexo do agressor ou de quem esteja ocupando uma posição de dominação, o gênero dessa dominação patriarcal é masculino.

$\mathrm{O}$ que se destaca, portanto, é justamente essa lógica androcêntrica, chamada por Bourdieu (2011) de dominação masculina, que é incorporada em homens e mulheres, nas práticas sociais cotidianas, reproduzidas ao longo dos tempos, cristalizando-se de tal forma a serem percebidas como naturais - e não como os constructos sociais que são. Assim, em um processo que o autor chamou de violência simbólica, os ditos dominantes e dominados incorporam a lógica androcêntrica, passando a pensar o mundo e a si mesmos de acordo com essa lógica.

Embora a lógica da violência como forma de dominação e subjugação do outro, de demonstração de força e poder, seja marca da socialização de meninos, conforme mostra Cechetto (2004), trata-se de uma lógica de dominação masculina que se expressa também nas garotas quando concordam que o ciúme abre precedentes para agressões físicas, quando tomam seu revide como uma forma de igualdade em relação aos garotos, quando afirmam que isso é assumir uma prática masculina e quando agridem outra garota considerada rival usando justamente o discurso machista que coloca a vítima de agressão como culpada (sobretudo se ela não se comporta conforme ditames da feminilidade recatada).

Pensando nas possíveis rupturas com tais hegemonias de gênero reproduzidas e cristalizadas entre os adolescentes, reafirmamos a problematização crítica trazida por Judith Butler (2010), para quem gênero é um mecanismo normativo específico através do qual as noções de masculino e feminino são produzidas e naturalizadas, mas também é dispositivo de desconstrução e desnaturalização desses mesmos termos, possibilitando rupturas com tais instituídos, abrindo-se, portanto, espaços, brechas para a transformação. O estudo de Pulerwitz e Barker (2008) com jovens brasileiros do sexo masculinos mostra que o incentivo às normas de gênero mais igualitárias e equânimes está associado a menos violência entre parceiros. Nesse mesmo caminho, Murta et al. (2013) trazem resultados positivos de intervenção voltada para a construção de habilidades de resolução de conflitos baseada na perspectiva de gênero, indicando, por exemplo, maior redução em crenças sexistas e homofóbicas entre os participantes. Nesse sentido é que se deve pensar na construção de estratégias de prevenção à violência entre parceiros íntimos direcionadas aos adolescentes que tenham como norte a construção de modos de ser e de se relacionar mais equânimes em suas vivências afetivo-sexuais. Além de intervenções orientadas para a identificação de comportamentos abusivos e violência após sua ocorrência, é preciso investir na prevenção baseada em reflexões sobre gênero (Tolman et al,2003).

\section{Considerações Finais}

No campo das relações afetivo-sexuais, vivenciamos permanências e mudanças das relações de gênero. Entre as práticas sociais que vêm se transformando, testemunhamos maior similaridade entre os gêneros no que se refere às primeiras relações sexuais, a desvalorização da necessidade da virgindade antes do casamento e diferentes formas de vivenciar a conjugalidade. No campo social, políticas de enfrentamento da violência contra a mulher e a visibilidade de diferentes frentes de luta pela igualdade entre os gêneros vêm atravessando o modo de vida dos adolescentes, tornando-se bastante difundido o ideal de relações afetivo-sexuais mais igualitárias e simétricas. Expressando a coexistência entre visões tradicionais e visões mais igualitárias e simétricas - o que faz parte do processo de transformação cultural e dos valores sociais -, os resultados deste estudo revelam o quanto ainda persistem valores tradicionais que endossam a violência entre parceiros íntimos e que são usados pelos adolescentes como justificativa para agressões físicas contra seus namorados e namoradas.

Nossos resultados apontam para a necessidade de refletirmos sobre formas de vivência das relações afetivosexuais que não sejam meras reprodutoras de uma lógica de dominação. Urge construir outros modos de se relacionar que escapem às normas de gênero tradicionais, que reificam a violência como forma de resolução de conflitos. A 
perpetuação de práticas violentas se dá principalmente pela naturalização com que são percebidas e reproduzidas no cotidiano, inclusive por adolescentes. Se, por um lado, os jovens apresentam uma postura crítica em relação ao que se coloca socialmente como demanda a homens e mulheres, por outro, justamente pela sua inserção na sociedade, reproduzem, muitas vezes, visões que refletem desigualdades de gênero.

É necessário, portanto, um maior investimento de diversos setores - saúde, educação, mídia - no sentido desenvolver ações voltadas para os adolescentes visando à desconstrução de estereótipos de gênero. Se o objetivo é promover relações mais igualitárias, a violência como forma de resolver os conflitos nas relações afetivo-sexuais precisa ser seriamente problematizada e, sobretudo, desnaturalizada, assim como se deve pensar em estratégias de prevenção que se proponham, efetivamente, a trabalhar com as normas de gênero.

\section{Referências}

Aizenman, M., \& Kelley, G. (1988). The incidence of violence and acquaintance rape in dating violence relationships among college men and women. Journal of College Student Development, 29(4), 305-311.

Aldrighi, T. (2004). Prevalência e cronicidade da violência física no namoro entre jovens universitários do Estado de São Paulo/ Brasil. Psicologia: Teoria e Prática, 6(1), 105-120.

Ángel, M., \& Barraza, A. (2015). Violencia en el noviazgo: Perpretación, victimización y violencia mutua. Una revisión. Actualidades en Psicología, 29(118), 57-72. doi http://dx.doi. org/10.15517/ap.v29i118.16008

Arriaga, X. B., \& Foshee, V. A. (2004). Adolescent dating violence: Do adolescents follow in their friends', or their parents', footsteps? Journal of Interpersonal Violence, 19(2), 162-184.

Avanci, J. Q., \& Assis, S. G. (2011) Opções Metodológicas. In M. S. C. Minayo, S. G. Assis, \& K. Njaine (Orgs.), Amor e violência: Um paradoxo das relações de namoro e do 'ficar'entre jovens brasileiros (pp. 302-314). Rio de Janeiro: Fiocruz.

Bardin, L. (2011). Análise de conteúdo. Lisboa: Edições 70.

Beserra, M. A., Leitão, M. N. C., Fernandes, M. I. D., Scatena, L., Vidinha, T. S., Silva, L. M., \& Ferriane, M. G. (2015). Prevalência de violência no namoro entre adolescentes de escolas públicas de Recife/PE - Brasil. Revista de Enfermagem Referência, serIV(7), 91-99. doi: 10.12707/RIV15006

Borrego, J., Franco, L., Díaz, F. J., \& Molleda, C. B. (2014). Violencia en el noviazgo: Revisión bibliográfica y bibliométrica. Arquivo Brasileiro de Psicologia, 66(1), 1-17.

Bourdieu, P. (2011). A dominação masculina. Rio de Janeiro: Bertrand Brasil.

Brasil. (2006). Lei 11.340 de 07 de agosto de 2006 - Lei Maria da Penha.

Butler, J. P. (2010). Problemas de gênero: Feminismo e subversão de identidade. Rio de Janeiro: Civilização Brasileira.

Cechetto, F. R. (2004). Violência e estilos de masculinidade. Rio de Janeiro: FGV.
Cornelius, T. L.,Sullivan, K. T., Wyngarden, N., \& Milliken, J. C. (2009). Participation in prevention programs for dating violence: Beliefs about relationship violence and intention to participate. Journal of Interpersonal Violence, 24(6), 10571078. doi: 10.1177/0886260508319363

Dantas-Berger, S. M., \& Giffin, K. (2005). A violência nas relações de conjugabilidade: Invisibilidade e banalização da violência sexual? Cadernos de Saúde Pública, 21(2), 417-425. doi: 10.1590/S0102-311X2005000200008

Dobash, R. P., \& Dobash R. E. (2004). Women's violence to men in intimate relationships. British Journal of Criminology, 44, 324-349. doi: 10.1093/bjc/azh026

Fávero, M. H. (2010). Psicologia do gênero: Psicobiografia, sociocultura e transformações. Curitiba: Editora UFPR.

Feiring, C., Deblinger, E., Hoch-Espada, A., \& Haworth, T. (2002). Romantic relationship aggression and attitudes in high school students: The role of gender, grade, and attachment and emotional styles. Journal of Youth and Adolescence, 31, 373385. doi: 10.1023/A:1015680625391

Fernandez-Fuertes, A. A., \& Fuertes, A. (2010). Physical and psychological aggression in dating relationships of spanish adolescents: Motives and consequence. Child Abuse \& Neglect, 34, 183-191. doi: 10.1016/j.chiabu.2010.01.002

Follingstad, D. R., Wright, S., Lloyd, S., \& Sebastian, J. A. (1991). Sex differences in motivations and effects in dating aggression. Family Relations, 40, 51-57. doi: 10.2307/585658

Foshee, V. A., \& Reyes, H. L. (2011). Dating abuse: Prevalence, consequences and predictors. In R. J. R. Levesque (Ed.), Encyclopedia of Adolescence. New York: Springer Science.

Franco, L., Bellerín , L., Borrego, J., Díaz, F.J., \& Molleda, C. (2012). Tolerance towards dating violence in Spanish adolescents. Psicothema, 24(2), 236-242.

Frieze, I. H. (2000). Violence in close relationships - development of a research area: Comment on archer. Psychological Bulletin, $126,681-684$.

Frieze, I. H. (2005). Female violence against intimate partners: An introduction. Psychology of Women Quarterly, 29, 229-237. doi: 10.1111/j.1471-6402.2005.00217.x

Furlong, M., Felix, E., Simental, J., Greaf, J., Klein, A., Gonzales, M., \& Austin, G. (2004, October). Dating violence patterns of California adolescents. Paper presented at Persistently Safe Schools: The National Conference of the Hamilton Fish Institute on School and Community Violence, Washington, D. C.

Gamache, D. (1991). Domination and control: The social context of dating violence. In B. Levy (Ed.), Dating violence: Young women in danger (pp. 69-83). Seattle: Seal Press.

Gomes, R., Minayo, M. C. S., \& Silva, C. F. R. (2005). Violência contra a mulher: Uma questão transnacional, e transcultural das relações de gênero. In E. R. Souza \& M. C. S. Minayo (Orgs.), Impacto da violência na saúde dos brasileiros (pp. 117-140). Brasilia: Ministério da Saúde.

Gomez, A. M., Speizer, I. S., \& Moracco, K. E. (2011). Linkages between gender equity and intimate partner violence among urban Brazilian youth. Journal of Adolescent Health, 49(4), 393-399. doi: 10.1016/j.jadohealth.2011.01.016

Gregori, M. F. (1993). Cenas e queixas: Um estudo sobre mulheres, relações violentas e a prática feminista. Rio de Janeiro: Paz e Terra. 
Hamby, S., Nix, K., De Puy, J., \& Monnier, S. (2012). Adapting dating violence prevention to francophone Switzerland: A story of intra-western cultural differences. Violence and Victims, 27(1), 33-42.

Heilborn, M. L. (2009). Uma abordagem sociológica da adolescência. In S. R. Taquette (Org.), Aids, juventude, gênero, classe e raça (pp. 183-196). Rio de Janeiro: Eduerj.

Hokoda, A., Ramos-Lira, L., Celaya, P., Vilhaur, K., Angeles, M., Ruíz, S. ... Mora, M. D. (2006). Reliability of translated measures assessing dating violence among mexican adolescents. Violence and Victims, 21(1), 117-27

Jaycox, L. H., McCaffrey, D., Eiseman, B., Aronoff, J., Shelley, G. A., Jackson, S. M., \& Seymour, F.W. (2000). Violence and sexual coercion in high school students' dating relationships. Journal of Family Aggression, 15, 23-36. doi: 10.1023/A: 1007545302987

Krug, E. G., Mercy, J. A., Dahlberg, L .L., \& Zwi, A. B. (2002). World report on violence and health. Genova: World Health Organization.

Murta, S., Franco, C T., Araújo, I., Nobre, L., Rodrigues, I., Miranda, A. A., \& Pereira dos Santos, B. R. (2013). Prevenção à violência no namoro e promoção de habilidades de vida em adolescentes. Psicologia USP, 24, 263-288. doi: 10.1590/ S0103-65642013000200005

Makepeace, J. M. (1981). Courtship violence among college students. Family Relations, 30(1), 97-102.

Makepeace, J. M. (1986). Gender differences in courtship violence victimization. Family Relations, 35(3), 383-388.

Malik, S., Sorenson, S. B., \& Aneshensel, C. S. (1997). Community and dating violence among adolescents: Perpetration and victimization. Journal of Adolescent Health, 21, 291-302. doi: 10.1016/S1054-139X(97)00143-2

Minayo, M. C. S. (2010). O desafio do conhecimento (11 ${ }^{\mathrm{a}} \mathrm{Ed}$.). São Paulo: Hucitec.

Minayo, M. C. S., Souza, E. R., Constantino, P., \& Santos, N. C. (2005). Métodos, Técnicas e relações em triangulação. In M. C. S. Minayo, S. G. Assis, \& E. R. Souza (Orgs.), Avaliação por triangulação de métodos: Abordagem de programas sociais (pp. 71 - 104). Rio de Janeiro: Fiocruz.

Minayo, M. C. S., Njaine, K., \& Assis, S. G. (2004). Cuidar cuidando dos rumos: Conversa com educadores sobre avaliação de programas sociais. Rio de Janeiro: Fiocruz.

Minayo, M. C. D. S., Assis, S. G. D., Souza, E. R. D., Njaine, K., Deslandes, S. F., Silva, C. M. F. P. D., ... Monteiro, M. D. C. N. (1999). Fala, galera: Juventude, violência e cidadania no Rio de Janeiro. Rio de Janeiro: Garamond.

Molidor, C., \& Tolman, R. M. (1998). Gender and contextual factors in adolescent dating violence. Violence Against Women, 4(2), 180-194.

Nascimento, F. S., \& Cordeiro, R. L. M. (2011). Violence in relationships according to young residents of Recife, Brazil. Psicologia \& Sociedade, 23(3), 516-525. doi: 10.1590/S010271822011000300009

Pulerwitz, J., \& Barker, G. (2008). Measuring attitudes toward gender norms among young men in Brazil. Men Masculinities, 10, 322-338. doi: 10.1177/1097184X06298778

O'Keefe, M., \& Treister, L. (1998). Victims of dating violence among high school students: Are the predictors different for males and females? Violence Against Women, 4, 195-223.
O'Keefe, M. (1997). Predictors of dating violence among high school students. Journal of Interpersonal Violence, 12, 546568.

O'Keefe, N. K., Brockopp, K., \& Chew, E. (1986). Teen dating violence. Social Work, 31(6), 463-468.

Oliveira, Q. B. M., Assis, S. G., Njaine, K., Oliveira, R. V. C. (2011). Violências nas relações afetivo-sexuais. In M. S. C. Minayo, S. G. Assis, \& K. Njaine (Orgs.), Amor e violência: Um paradoxo das relações de namoro e do 'ficar' entre jovens brasileiro (pp. 87-140). Rio de Janeiro: Fiocruz.

Oliveira, R. V. C., Assis, S. G., Njaine, K., Minayo, M. C. S., Oliveira, Q. B.M., Ribeiro, F. M. L., ... Pire, T. O. (2011). A pesquisa e os jovens que dela participaram. In M. S. C. Minayo, S. G. Assis, \& K. Njaine (Orgs.), Amor e violência: Um paradoxo das relações de namoro e do 'ficar'entre jovens brasileiro (pp. 45-54). Rio de Janeiro: Fiocruz.

Roscoe, B., \& Callahan, J. E. (1985). Adolescents' self-report of violence in families and dating relations. Adolescence, 20, 545-553.

Saavedra, R., Machado, C., Martins, C., \& Vieira, D. (2011). Inventário de conflitos nas relações de namoro entre adolescentes (ICRNA). In M. R. Simões, C. Machado, \& M. Gonçalves (Coords.), Instrumentos e contextos de avaliação psicológica (pp. 269-283). Coimbra: Almedina.

Saffioti, H. I. B. (1987). O poder do macho. São Paulo: Moderna.

Saffioti, H. I. B. (2004). Gênero, patriarcado e violência. São Paulo: Fundação Perseu Abramo.

Schiff, M., \& Zeira, A. (2005). Dating aggression and sexual risk behaviours in a sample of at-risk Israeli Youth. Child Abuse \& Neglect, 29, 1249-1263. doi: 10.1016/j.chiabu.2005.04.007

Sears, H. A., Byers, E. S., Whelan, J. J., \& Saint-Pierre, M. (2006). If it hurts you, then it is not a joke: Adolescents' ideas about girls and boys use of abusive behavior in dating relationships. Journal of Interpersonal Violence, 21(9),1191-1207. doi: 10.1177/0886260506290423

Shen, A. C., Chiu, M. Y., \& Gao, J. (2012). Predictors of dating violence among chinese adolescents: The role of gender-role beliefs and justification of violence. Journal of Interpersonal Violence, 27(6), 1066-1089. doi: 10.1177/0886260511424497

Taquette, S. R., Ruzany M. H., Meirelles, Z., \& Ricardo, I. (2003). Relacionamento violento na adolescência e risco de DST/ AIDS. Cadernos de Saúde Pública, 19, 1437-1444. doi: 10.1590/S0102-311X2003000500022

Tolman, D. L., Spencer, R., Rosen-Reynoso, M., \& Porche, M. V. (2003). Sowing the seeds of violence in heterosexual relationships: Early adolescents narrate compulsory heterosexuality. Journal of Social Issues, 59, 159-178. doi: 10.1111/1540-4560.t01-1-00010

Vagi, K. J., Rothman, E. F., Latzman, N. E., Tharp, A. T., Hall, D. M., \& Breiding, M. J. (2013). Beyond correlates: A review of risk and protective factors for adolescent dating violence perpetration. Journal of Youth and Adolescence, 42(4), 633-49. doi: 10.1007/s10964-013-9907-7

Williams, J. R., Ghandour, R. M., \& Kub, J. E. (2008). Female perpetration of violence in heterosexual intimate relationships: Adolescence through adulthood. Trauma, Violence, and Abuse, 9(4), 227-249. doi: 10.1177/1524838008324418 
Wolfe, D. A., Scott, K., Reitzel-Jaffe, D., Wekerle, C., Grasley, C., \& Straatman, A, L. (2001). Development and validation of the conflict in adolescent dating relationships inventory. Psychological Assessment, 13(2), 277-293.

Wolfe D. A., Scott K, Wekerle, C., \& Pittman A. L. (2001) Child maltreatment: risk of adjustment problems and dating violence in adolescence. Journal of American Academy of Child and Adolescent Psychiatry, 40(3). doi:10.1097/00004583200103000-00007
Zuma, C. E, Mendes C. H. F., Cavalcanti, L. F., \& Gomes, R. (2009). Violência de gênero na vida adulta. In K. Njaine (Org.), Impactos da violência na saúde (pp. 149-181). Rio de Janeiro: Fundação Oswaldo Cruz.

Recebido em 04.02.2013

Primeira decisão editorial em 22.01.2016

Versão final em 06.06.2016 Aceito em 19.07.2016 